\title{
A busca ativa como princípio político das práticas de cuidado no território ${ }^{1}$
}

\section{The active search as political principle of practices of care in the territory}

\section{Ruben Artur Lemke*}

Professor do Curso de Psicologia da Universidade para o Desenvolvimento do Estado e da Região do Pantanal - UNIDERP, Campo Grande, MS, Brasil

\section{Rosane Azevedo Neves da Silva**}

Professora do Programa de Pós-Graduação em Psicologia Social e Institucional da Universidade Federal do Rio Grande do Sul - UFRGS, Porto Alegre, RS, Brasil

\begin{abstract}
RESUMO
Originalmente um procedimento estritamente técnico de ação em vigilância epidemiológica, a expressão busca ativa passou também a denotar uma postura política de trabalho no território. Este artigo visa mostrar como determinadas práticas no campo da saúde, sobretudo o trabalho dos acompanhantes terapêuticos, dos Agentes Comunitários de Saúde e dos redutores de danos, sob a consigna da desinstitucionalização e da integralidade, transformaram o sentido atribuído a esta expressão. Pretende-se também apresentar o potencial de politização das práticas e abertura de um campo de possíveis para a produção de novos sentidos contidos nos conceitos de desinstitucionalização e integralidade. Por último, através das reflexões de Hannah Arendt sobre o princípio de vita activa, o artigo pretende problematizar a atividade que está no cerne da experiência destes trabalhadores itinerantes e de suas práticas no território.
\end{abstract}

PALAVRAS-CHAVE: Busca ativa, Saúde mental, Atenção básica, Cuidado, Território.

\section{ABSTRACT}

Originally a purely technical procedure for action in epidemiological surveillance, the term active search also became denote a political position of work in the territory. This article aims to show how certain practices in the health field, especially the work of therapeutic accompanying, community health agent and harm reduction works, down under the deinstitutionalization and integrality, transformed the meaning assigned to that expression. It is also present the potential for politicization of practice and opening a field of potential for the production of new meanings contained in the concepts of deinstitutionalization and integrality. Finally, through the reflections of Hannah Arendt about the principle of vita active, the paper aims to problematize the activity that is central to the experience of the itinerant workers and its practices in the territory.

KEYWORDS: Active search, Mental health, Primary health care, Care, Territory. 


\section{I ntrodução}

A noção de território se tornou um princípio organizador dos processos de trabalho nas atuais políticas de Saúde Mental e Atenção Básica. No contexto de consolidação do Sistema Único de Saúde, as duas políticas têm como desafio construir práticas de cuidado pautadas por uma lógica territorial e, desta forma, transpor as ações de saúde para mais perto do "mundo do usuário" e de seus modos de vida.

Os princípios de desinstitucionalização e integralidade são operadores conceituais que, além de orientar estas políticas e demarcar a diferença que as reformas Psiquiátrica e Sanitária pretendem imprimir nas práticas de cuidado, apontam para uma determinada concepção de território. Mais do que um extenso estático ou um recorte geográfico, estes princípios apontam para uma dimensão existencial do território, assim como para um engajamento político nas práticas de cuidado.

Segundo Haesbaert (2004), a territorialidade é uma dimensão constitutiva da condição humana e o próprio conceito de sociedade implica sua espacialização, sua territorialização, pois não há como definir indivíduo, comunidade ou sociedade sem inseri-los em determinado contexto geográfico. Na época da institucionalização do SUS, foi na obra do geógrafo Milton Santos que os sanitaristas brasileiros se apoiaram para construir a ideia de território-processo presente na concepção dos Distritos Sanitários ${ }^{2}$ no Brasil (SILVA JUNIOR, 1997). Na obra do referido geógrafo se destacam os conceitos de território usado ${ }^{3}$ e espaço banal.

O território usado é compreendido pelo autor como "um todo complexo onde se tece uma trama de relações complementares e conflitantes [...] convidando a pensar processualmente as relações estabelecidas entre o lugar, a formação socioespacial e o mundo" (SANTOS, 2000, p. 104 e 105). Território usado é o chão apropriado por um coletivo, sua morada, base da vida, do trabalho, das trocas materiais e espirituais. "É o fato e o sentimento de pertencer àquilo que nos pertence (SANTOS, 2003, p. 96, 97)". Pois território é o espaço habitado, percorrido e humanizado ${ }^{4}$.

O espaço banal ${ }^{5}$ é a realidade espaço-temporal compartilhada, “ [...] é o espaço de todas as dimensões do acontecer, de todas as determinações da totalidade social. É uma visão que incorpora o movimento do todo [...]" (SANTOS, 2000, p. 104) O espaço banal, como dimensão espacial do cotidiano, é ao mesmo tempo précondição e convite à ação política, porque é neste espaço banal que se superpõem as coexistências e onde se fundem as noções e as realidades de tempo e de espaço. É neste cotidiano compartilhado, onde as diferentes pessoas e instituições cooperam e competem que as ações políticas se territorializam no confronto entre as formas de organização e a espontaneidade humana (SANTOS, 2002). 
Guattari e Rolnik (1986) entendem território como um plano que comporta tanto o espaço vivido como um sistema dentro do qual alguém se sente "em-casa". Território é primeiramente uma apropriação subjetiva, é o modo como se agencia o desejo nos espaços e tempos sociais.

No campo das políticas de Saúde Mental e Atenção Básica e no delicado espaço de articulação destas, três experiências de trabalho têm se destacado na tarefa de conferir um sentido existencial à palavra território. Referimos-nos às práticas dos acompanhantes terapêuticos (ats), dos Agentes Comunitários de Saúde (ACS) e dos redutores de danos, enquanto tecnologias que, apesar de suas diferenças, guardam em comum a característica principal de operar em movimento e efetuar ações de saúde no território de vida dos usuários e próximo ao seu cotidiano.

Estas três experiências adquiriram uma consistência própria, vinculando-se de modo estreito às problemáticas suscitadas pelos movimentos das reformas Sanitária e Psiquiátrica e com a institucionalização do SUS, passando a ter uma relevância estratégica na construção de um modelo territorial de cuidado.

A literatura tem se ocupado majoritariamente em nomear, classificar, compreender e legitimar estas experiências. Assim, por exemplo, podemos encontrar a preocupação em entender se estas práticas no território são ações clínicas ou extraclínicas, se produzem abertura, modificação ou transgressão do setting. Colocamo-nos ao lado daqueles que consideram pertinente neste momento dirigir a atenção àquilo que estas experiências têm a nos ensinar sobre a clínica, sobre as práticas de cuidado e sobre a consecução das políticas públicas de saúde no território.

Os textos da Política Nacional de Atenção Básica e da Política Nacional de Atenção Integral aos Usuários de Álcool e Outras Drogas, assim como as portarias e normativas da Política Nacional de Saúde Mental, nos deixam algumas pistas sobre as expectativas que as políticas públicas atuais depositam nestes trabalhadores itinerantes no exercício de suas práticas: trabalhar numa lógica territorial, manter uma relação com a população do território baseada no vínculo, no acolhimento e na responsabilização, assim como ter uma postura de busca ativa em relação aos problemas de saúde no território (BRASIL, 2004a, 2004b, 2004c, 2005a, 2007).

O presente artigo tem como principal objetivo evidenciar como as práticas produzidas por estes trabalhadores, sob a consigna da desinstitucionalização e da integralidade, transformaram o sentido atribuído ao termo busca ativa. Originalmente um procedimento estritamente técnico de ação em vigilância epidemiológica, o termo passou a denotar também uma postura política de trabalho no território. Como objetivo secundário, pretendemos demonstrar, através da torção de sentido deste termo, o potencial de politização 
das práticas e a abertura de um campo de possíveis para a produção de novos sentidos contidos nos conceitos de desinstitucionalização e integralidade. Por último, pretendemos lançar mão do princípio de vita activa em Hannah Arendt, para pensar esta atividade que está no cerne da experiência destes trabalhadores itinerantes e de suas práticas no território.

\section{A busca ativa como princípio político das práticas de cuidado}

Uma importante postura da Saúde Coletiva é considerar as práticas de saúde não como práticas médicas ou psiquiátricas, mas como práticas sociais (MATTOS, 2001) e, portanto, políticas. Um deslocamento imprescindível para a materialização dos princípios do SUS é retirar, segundo a expressão de Guattari (1990), o avental branco da neutralidade técnica e ingressar no movimento de uma ação política. No plano das políticas de Saúde Mental e de Atenção Básica, os conceitos de desinstitucionalização e integralidade apontam justamente para uma ação política no território.

Segundo Rotelli (1992), "a desinstitucionalização requer a relação com um território" ( $p$. 47), o "deslocamento da intervenção terapêutica para o contexto social das pessoas" (p. 20). Este deslocamento, não pode ocorrer no sentido de medicalizar, psiquiatrizar ou psicologizar o território, mas no sentido de romper com o mandato social de controle e normalização, inventar projetos de vida e produzir regimes de sociabilidade que tornem possível a existência da diferença. Aspirando, em última instância, mudar a relação do corpo social com a loucura e tendo sempre como horizonte a ideia de que "se a realidade é essencialmente construída, pode ser substancialmente modificada" (AMARANTE, 1996, p.21). Uma repercussão direta da desinstitucionalização nas práticas é a recusa do isolamento do usuário como método de terapêutica. Uma prática de cuidado só pode ser consequente se for relativa ao sujeito em seu contexto existencial. A integralidade é um operador conceitual que porta uma crítica radical às lógicas reducionistas e contém a intenção de produzir mudanças profundas nas ações de saúde, contextualizando-as aos modos de vida dos usuários e aproximando-as das reais necessidades de saúde. Portanto, a integralidade supõe uma postura de escuta ativa dos problemas numa relação de alteridade com o usuário. Ao definir que o objeto de trabalho em saúde é o sujeito em sofrimento em seu contexto de vida, produz-se a opção política de trabalhar numa lógica territorial e de incluir nas práticas a dimensão da subjetividade que caracteriza os sujeitos sociais que portam aspirações, desejos e histórias singulares de vida. As intervenções não se restringem ao indivíduo e seus sistemas biológicos, mas se direcionam a um sujeito em relação no seu contexto de existência. Uma prática integral também significa a construção de campos de mediações para a leitura das reais necessidades de saúde no território, para além da demanda 
espontânea, que é construída historicamente (MATTOS, 2001; MERHY, 2005; PINHEIRO, GUIZARDI, MACHADO, GOMES, 2005; SILVA, STELET, PINHEIRO, GUIZARDI, 2005).

Os dois princípios, portanto, colocam o território como um princípio organizador das práticas e ao levar em conta a dimensão da subjetividade dos usuários como atores sociais, definem o ingresso dos trabalhadores no território como uma ação política. É interessante observar que atualmente podemos encontrar na literatura ou nos textos orientadores das políticas, o uso da expressão busca ativa para indicar justamente este caráter político das práticas no território.

De fato, é possível observar em alguns movimentos, a transformação de um procedimento estritamente técnico em um princípio político e o concomitante abandono de uma pretensa neutralidade científica no uso da noção de busca ativa ${ }^{6}$. O sentido mais comum atribuído à busca ativa, muito usado nas ações de Vigilância Epidemiológica, Vigilância Sanitária e Saúde do Trabalhador, é ir à procura de indivíduos com o fim de uma "identificação sintomática", principalmente das doenças e agravos de notificação compulsória (BRASIL, 2001). Busca ativa é um procedimento de suma importância no conjunto de ações em vigilância epidemiológica de investigação de campo, e tem como objetivo a identificação precoce de casos suspeitos e uma rápida confirmação para orientar adequadamente a aplicação de medidas de controle (BRASIL, 2005b).

Este é o sentido estrito do termo, contudo os princípios do SUS, de modo especial os operadores conceituais da desinstitucionalização e integralidade produziram uma torção no sentido de busca ativa, uma subversão de seu uso. Busca ativa também passou a ser entendida como um movimento de ir à contracorrente do automatismo da demanda espontânea, no sentido de cartografar as necessidades de saúde para além dos agravos de notificação compulsória de determinado território.

Trabalhar na lógica da busca ativa é uma das expectativas que se tem sobre a prática dos trabalhadores no território e é bastante mencionada na legislação e nos textos técnicos de saúde, além de ser considerada uma atribuição de todos os profissionais da Estratégia de Saúde da Família (ESF) na Política Nacional de Atenção Básica (BRASIL, 2007). Esse sentido pode ser encontrado na referida política com o termo "postura pró-ativa frente aos problemas de saúdedoença da população" (BRASIL, 2007, p. 22).

E esse também foi o sentido que os redutores de danos conferiram ao termo com suas práticas, tomando-o do modelo de identificação sintomática e subvertendo seu sentido para um uso político de manter uma postura ativa para acessar o mundo dos usuários e suas necessidades. A torção de sentido provocou o deslocamento de um mero identificar um quadro sintomático para o movimento de acessar 
o território do usuário, estabelecer vínculo terapêutico e se integrar ao seu meio cultural ${ }^{7}$.

Operando no sentido estrito do termo busca ativa, as práticas permanecem coladas ao que Tenório (2001) chamou de modelo sintomatológico, no qual o quadro sintomático toma primeiro plano e o sujeito fica obturado. Trabalhar numa lógica de busca ativa dentro de um modelo estritamente sintomatológico pode converter as ações de Saúde Mental e Atenção Básica no território em pura estratégia de controle sobre as populações vulneráveis. Em Ayres (2004, p. 9), podemos encontrar uma expressão que foge completamente do modelo sintomatológico, afirmando o potencial político das ações no território: "busca ativa de projetos de felicidade". Esta expressão denota a idéia de uma intervenção que incida no território existencial do usuário, que leve em conta sua singularidade, seus desejos e aspirações. Ayres (2004) considera busca ativa de projetos de felicidade, o modo como os trabalhadores se engajam ativamente nos projetos existências dos usuários e considera este engajamento um elemento crucial para a reconstrução ética, política e técnica do cuidado no SUS, dentro de uma proposta de integralidade das práticas.

O princípio de busca ativa é talvez a característica mais marcante das práticas itinerantes, presente desde o sanitarismo campanhista, seja na busca de lugares insalubres de emanação de miasmas, de vetores ou de indivíduos contaminados, sempre na luta contra as doenças contagiosas (JUNIOR; NOGUEIRA, 2002; LIMA, 2002). Com o conjunto de transformações propostas pelos movimentos de Reforma Sanitária e Reforma Psiquiátrica, as práticas itinerantes no território passaram a ter função política diferente da identificação de riscos de contágio e de quadros sintomáticos, deslocando a busca ativa do modelo sintomatológico que caracteriza a medicina flexneriana e a psiquiatria.

O termo "busca ativa" também passou a ser usado para denotar uma postura política de trabalho sob a bandeira da integralidade do cuidado, que pressupõe atender às necessidades de saúde para além da demanda espontânea (MATTOS, 2001). A busca ativa de quadros sintomáticos é, sem dúvida, uma ação importante em diversas frentes no âmbito do SUS, mas é preciso prudência para que o modelo sintomatológico não se imponha e acabe por capturar o sentido da busca ativa, tornando inócuo o seu potencial de ação política no território no momento em que se converte em pura estratégia de controle das populações. A atividade está no cerne da experiência dos trabalhadores itinerantes. Mas o que caracteriza exatamente essa atividade? A compreensão da busca ativa como uma postura política pode ser pensada a partir das considerações que Hannah Arendt (2005) faz sobre o princípio da vita activa como condição inerente à existência humana. Por vita activa ${ }^{8}$ a autora entende três dimensões 
da existência que são: o labor, que se refere aos processos biológicos do corpo humano, sendo que a condição humana do labor é a própria vida; o trabalho, que se refere ao mundo artificial produzido pelo homem e cuja condição humana é o que a autora denominou mundanidade; e, por último, a ação. Esta a "única atividade que se exerce diretamente entre os homens sem a mediação das coisas ou da matéria, correspondente à condição humana da pluralidade" (ARENDT, 2005, p. 15).

Segundo Arendt (2005), todas as condições da existência humana - a vida, a mundanidade e a pluralidade - têm relações com a política. Mas a pluralidade é a condição por excelência de toda a vida política porque os homens vivem num mundo habitado por outros homens ${ }^{9} \mathrm{e}$ onde, apesar de todos serem humanos, são diferentes em seus modos de ser.

\begin{abstract}
A ação seria um luxo desnecessário, uma caprichosa interferência com as leis gerais do comportamento, se os homens não passassem de repetições interminavelmente reproduzíveis do mesmo modelo, todas dotadas da mesma natureza e essência. (ARENDT, 2005, p. 16)
\end{abstract}

Esse entendimento da ação como atividade política inerente à condição da existência humana é um caminho para deslocar o movimento produzido pelos trabalhadores no território para além do plano estritamente espacial. Nisso reside a possibilidade de situar as práticas em outro plano, no plano político, que Arendt (2005) chama de esfera pública e que é o espaço do agir político, no interstício que há entre os sujeitos da ação política.

Mas, segundo Ortega (2000), esse agir de que fala Hannah Arendt não é executar um comportamento como uma peça de engrenagem de um imenso aparelho burocrático. É um agir que não tem a ver com replicação, mas com criação. Do mesmo modo, o espaço público de que fala a autora não é um espaço homogêneo, preso ao Estado, mas um espaço político que se apresenta com uma multiplicidade de aspectos e que não precisa de um suporte institucional para existir. Há muita possibilidade de ação e muitos espaços podem ser criados, no entanto faz-se necessário que os sujeitos se articulem por meio do discurso e da ação, começando de algum modo a agir, criar e experimentar. Nesse sentido, os movimentos de Reforma Psiquiátrica e Sanitária forjaram um discurso que agrega atores políticos, que não depende exclusivamente do abrigo de uma instituição para agir.

A política é entendida por Arendt como um agir em liberdade e o exercício político como uma atividade de criação, o desenvolvimento de novas formas de amor mundi, o afrontamento do instituído e a experimentação de novas formas de sociabilidade: o que move a 
política é "uma vontade de agir, de transgredir e superar os limites" (ORTEGA, 2000, p. 24).

Segundo Arendt (2005), a expressão vita activa sempre teve a conotação negativa no ocidente de "inquietude", dentro de uma tendência apontada por Rolnik (2006, p. 20) que valoriza a quietude e recusa as turbulências da vida em sua natureza de perpétuo processo criativo, assim como menospreza a fragilidade desses processos. Desse modo, a inquietude, como resultado da ação de forças que produzem incômodo, tem um valor político muito importante, o de propulsão, o de uma força motriz que faz agir, que nos tira de nossa inércia sedentária, colocando-nos em movimento e nos acoplando às "várias formas de engajamento nas coisas deste mundo" (ARENDT, 2005, P. 26) ${ }^{10}$.

Segundo Ortega (2000), a ação política, tal como a define Arendt, tem a propriedade de produzir subjetividade, pois é no espaço intersubjetivo da esfera pública que os sujeitos se constituem. A pluralidade é a condição humana de possibilidade para a ação e é por meio desta e do discurso que os homens se distinguem em suas diferenças. Mas não se trata de uma visão essencialista da subjetividade, em que ação e discurso seriam modos de expressar, modos de revelar o sujeito imutável por trás das ações. Não se trata de uma revelação, mas de uma produção. O sujeito constitui-se de modo coextensivo às suas ações.

Ortega (2000) afirma que agir politicamente é arriscar, porque requer coragem para a experimentação e para iniciar um processo que é irreversível e imprevisível. Só é possível agir “[...] se sairmos da esfera da segurança e confrontarmos o novo, o aberto, o contingente, se aceitarmos o encontro e o convívio com novos indivíduos, o desafio do outro, do estranho e desconhecido, $[\ldots]$ como forma de [...] recriar o amor mundi" (ORTEGA, 2000, p. 32).

De acordo com Ortega (2000) é preciso lembrar que Arendt distingue a fabricação da ação. Fabricar é agir baseado em cálculos de controle dos resultados, supostamente previsíveis a partir das ações. Um exemplo de fabricação na área da saúde são as rotineiras intervenções unilineares do modelo sintomatológico, de diagnóstico, prescrição e prognóstico com o objetivo definido de esbatimento de determinado quadro sintomático. O agir político, ao contrário, é a erupção de algo novo que quebra o automatismo de repetição da rotina burocrática do mundo do trabalho, iniciando um processo com desenlace desconhecido. Trata-se de uma interrupção na mecânica das repetições e a introdução do acaso e da diferença. Mas não incorpora a novidade de modo caótico: é um fértil acoplamento entre a consistência do conhecido e a fragilidade criativa do novo.

O agir humano é o nascimento do sujeito político. Arendt (2005) utiliza a palavra milagre para se referir à interrupção de processos naturalizados e considera que a capacidade de produzir milagres e 
transgredir limites é inerente ao agir humano. Mas, segundo Ortega (2000), contra esse potencial do agir e do pensar humano, ergueu-se toda a tradição filosófica ocidental com a intenção de acabar com o imprevisível, de domesticar o novo e o desconhecido, estabilizando os assuntos humanos pela criação do que o autor chama de ordem antipolítica.

Ortega (2000) afirma que Arendt não tinha a intenção de prescrever como uma norma universal o agir político. Ao invés disso, o que Arendt fez foi, através de um apelo retórico, demonstrar como é prazenteiro esse envolvimento nos negócios do mundo, a alegria que acompanha as experimentações e o gozo que produz estar implicado nessa condição fundamental da existência humana que é a ação política.

A contribuição de Arendt (2005) para pensar o agir político nas práticas de saúde no território aponta para a possibilidade de se produzir uma nova relação com o trabalho, baseada no prazer da experiência e da ação, na responsabilidade e no amor para com os negócios do mundo. Esta nova relação com o trabalho produziria efeitos também na relação com os usuários, que passariam a ser considerados como co-atores políticos.

No entanto, quando as ações em saúde se deslocam para o território de vida dos usuários com a crise generalizada das instituições disciplinares e seus meios de confinamento, segundo Deleuze, correse constantemente o risco de ver "formas ultra-rápidas de controle ao ar livre" progressivamente irem substituindo as disciplinas "que operam na duração de um tempo fechado" (DELEUZE, 1992, p. 220). Este deslocamento do cuidado das instituições de confinamento para o território faz com que as relações de poder se atualizem de modo diferente. Nas instituições de arquitetura disciplinar, como o manicômio, é comum que se estabeleçam estados de dominação, que, segundo Foucault (2006), é quando as relações de poder se imobilizam e fica bloqueada qualquer possibilidade de reversão do movimento.

Quando as ações de saúde deslocam-se para o território dos usuários e o território é tomado como um espaço político por excelência, as relações de poder podem se colocar em movimento, tensionando as práticas de trabalhadores e usuários.

Segundo Foucault (2006, p. 277), "se há relações de poder em todo campo social é por que há liberdade por todo lado". Embora as políticas de saúde também expressem o exercício do biopoder ${ }^{11}$, o fato é que no território as coisas se tornam mais complexas. Se as estratégias de controle tornam-se sutis e voláteis, é preciso lembrar também que se ampliam as possibilidades de resistência ${ }^{12}$ dos usuários, suas estratégias para quebrar cristalizações e bloqueios nas relações de poder. O fato é que os usuários são atores políticos que, pela situação de saúde ou por determinadas vulnerabilidades, podem 
estar jogando com bastante desvantagem os jogos de poder. Pensando desse modo, se integra ao trabalho em saúde cultivar o que Foucault (2006) denominou práticas de liberdade ${ }^{13}$ e, para isso, é preciso fortalecer os atores que estão em desvantagem, seja cuidando de uma afecção do corpo, seja ajudando a adquirir um direito social ou permitindo a saída de uma relação afetiva de sujeição, mantendo móveis as relações de poder.

Por prática de liberdade no contexto do cuidado é possível entender tanto o agir político dos trabalhadores como a situação desejada de potencializar o usuário como agente político no seu modo de andar na vida, ou seja, ampliar o grau de liberdade com que vive a sua existência. Desse modo, o cuidado também pode ser entendido como um plano que constitui trabalhadores e usuários como sujeitos éticos e políticos de suas ações. Pensar o trabalho desta forma é fazer do território das práticas um plano no qual os diversos atores possam, por meio de seus discursos e de suas ações, estilizar a existência na presença de outros atores políticos (FOUCAULT, 2006, ORTEGA, 2000).

Assim, de modo indissociável à política e à ética, soma-se o plano da estética no cuidado. Esse plano se refere tanto à criação como aos modos de percepção. Criação no sentido de criar nas práticas a possibilidade de estilizar a existência ${ }^{14}$ como forma de singularização frente a normas sociais vigentes e às políticas de subjetivação serializantes (FOUCAULT, 2006, GUATTARI, ROLNIK, 1986), e conceber o cuidado como invenção de vida ou criação das condições de possibilidade para a existência, como defendem os teóricos da desinstitucionalização (ROTELLI, LEONARDIS, MAURI, 1992).

Percepção, porque as práticas territoriais requerem uma amplitude de olhar, que não se foca mais em indivíduos que se movem em um extenso, mas no território existencial, o que exige uma atenção em sua processualidade ${ }^{15}$ para perceber a tônica da necessidade em uma intensidade que emerge no cipoal de complexidade do território. Seja de uma relação que se tornou opressora, um modo de ser despotencializado diante da vida, uma afecção no corpo ou um direito social obstruído.

Criação e percepção estão ligadas ao que Guattari (1992, p.130) denomina "potência estética do sentir". Concebendo as práticas de cuidado sob o prisma do paradigma estético proposto pelo autor, política, ética e estética são três planos indissociáveis: política como movimento do corpo na ação em liberdade; ética como movimento do pensamento na crítica aos modos de existência; e estética como movimento de ampliação da percepção. Três componentes importantes na construção de um cuidado territorialmente contextualizado. 


\section{Considerações finais}

A busca ativa, entendida como um princípio político dos processos de trabalho demonstra todo um campo de possibilidades das práticas de saúde no território. Se entender a busca ativa como procedimento técnico de identificação sintomática supõe uma compreensão geométrica do território, entender a busca ativa como principio político de uma lógica territorial de cuidado supõe a relação com um território que não é mais um extenso estático, mas um campo movente de forças, um tecido no qual a subjetividade se produz e no qual a vida se expande ou é constrangida em seu movimento. A busca ativa se torna um princípio político de luta em defesa da vida, quando os trabalhadores da saúde rompem com os automatismos, seja do pensamento, seja da percepção, possibilitando, deste modo, a abertura para um plano de invenção, no qual a potência política de seus movimentos possa ser explorada. Criando nas práticas, linhas de fuga para escapar do mandato de controle e homogeneização do social.

\section{Referências Bibliográficas}

AYRES, J. R. C. M. O cuidado, os modos de ser (do) humano e as práticas de saúde. Saúde e sociedade, São Paulo, v.13, n.3, p.1629, set-dez. 2004.

AMARANTE, P.D.C. O homem e a serpente: outras histórias para a loucura e a psiquiatria. Rio de J aneiro: Fiocruz, 1996.

ARENDT, H. A condição humana. Rio de Janeiro: Forense Universitária, 2005.

BRASIL. Ministério da Saúde. Organização Pan-Americana da Saúde no Brasil. Doenças relacionadas ao trabalho: manual de procedimentos para os serviços de saúde. (Org: DIAS, E. C. Colaborador: ALMEIDA, I. M). Brasília: Ministério da Saúde do Brasil, 2001

Ministério da Saúde. Secretaria de Atenção à Saúde. Legíslação em saúde mental. 1990 - 2004. Brasília, DF, 2004a.

- Departamento de Ações Programáticas Estratégicas. Saúde mental no SUS: os Centros de Atenção Psicossocial. Brasília, DF, 2004b.

Secretaria de Atenção à Saúde. SVS/CN-DST/AIDS. A política do Ministério da Saúde para atenção integral a usuários de álcool e outras drogas. 2.ed. rev. ampl.- Brasília, DF, 2004c.

Secretaria de Atenção à Saúde. DAPE. Coordenação Geral de Saúde Mental. Reforma psiquiátrica e política de saúde mental no Brasil. Documento apresentado à Conferência Regional de Reforma dos Serviços de Saúde Mental: 15 anos depois de Caracas. OPAS. Brasília, novembro de 2005a.

Secretaria de Vigilância em Saúde. Guia de vigilância epidemiológica. 6. ed. Brasília, DF, 2005b. 
Secretaria de Atenção à Saúde. Departamento de Atenção Básica. Política Nacional de Atenção Básica. Brasília, DF, 2007. DELEUZE, G. Conversações. Rio de Janeiro: Ed. 34, 1992. FOUCAULT, M. Não ao sexo rei. In: de J aneiro: Graal, 1999, p. 229-242. Microfísica do poder. Rio A ética do cuidado de si como prática de liberdade. In: Ditos e escritos v. 5. Ética, Sexualidade, Política. Organização e seleção de textos: Manoel Barros da Motta. Rio de Janeiro: Forense Universitária, 2006, p. 264-287.

GUATTARI, F. As três ecologias. Papirus Editora: Campinas, 1990. $\overline{3} \overline{4}, \overline{1} 992$.

Caosmose: um novo paradigma estético. Rio de Janeiro: Ed.

GUATTARI, F.; ROLNIK, S. Micropolítica: cartografias do desejo. Petrópolis: Vozes, 1986.

HAESBAERT, R. C. O mito da desterritorialização: do fim dos territórios à multiterritorialidade. Rio de Janeiro: Bertrand Brasil, 2004.

JUNIOR, J. B. R.; NOGUERIA. As condições de saúde no Brasil. In: FILKELMAN, J. (Org.). Caminhos da saúde pública no Brasil. Rio de Janeiro: Editora da Fiocruz, 2002, p. 115-234.

KASTRUP, V. Cartografias da invenção: pistas e políticas de um método de pesquisa. In: SEMINÁRIO ORAL PPG PSI/UFRGS, mar. 2007a, Porto Alegre. (informação oral).

- O funcionamento da atenção no trabalho do cartógrafo. Revista Psicologia e Sociedade, Porto Alegre, v.16, n.1, p. 15-22, jan./abr. 2007b.

LIMA, N. T. O Brasil e a Organização Pan-Americana da Saúde: Uma história em três dimensões. In: FILKELMAN, J. (Org.). Caminhos da saúde pública no Brasil. Rio de Janeiro: Editora da Fiocruz, 2002, p.24-116.

LOURAU, R. René Lourau na UERJ : análise institucional e práticas de pesquisa. Rio de J aneiro: EdUERJ, 1993.

MATTOS, R.A. Os sentidos da integralidade: algumas reflexões acerca de valores que merecem ser defendidos. In: PINHEIRO, R.; MATTOS, R. A. (Orgs.). Os sentidos da integralidade na atenção e no cuidado à saúde. Rio de Janeiro: UERJ-IMS, ABRASCO, 2001, p. 3963.

MERHY, E. E. Engravidando palavras: o caso da integralidade. In: PINHEIRO, R.; MATTOS, R. A. (Orgs.). Construção social da demanda: direito à saúde, trabalho em equipe, participação e espaços públicos. Rio de Janeiro: UERJ-IMS, ABRASCO, 2005, p. 195-206.

NARDI, H. C.; RIGONE, R. Q. Marginalidade ou cidadania? A rede discursiva que configura 0 trabalho dos redutores de danos. Psicologia em estudo, Maringá, v. 10, n.2, p. 273-282, maio/ago. 2005. 
NARDI, H. C.; SILVA, R. N. Ética e subjetivação: as técnicas de si e os jogos de verdade contemporâneos. In: GUARESCHI, N.; NÜNING, S. (Orgs.). Foucault e a psicologia. Porto Alegre: Abrapso Sul, 2005, p. 93-105.

ORTEGA, F. Para uma política da amizade: Arendt, Derrida, Foucault. Rio de Janeiro: Relume Dumará, 2000.

PINHEIRO, R.; GUIZARDI, F. L.; MACHADO, F. R. S.; GOMES, R. S. Demanda em saúde e direito à saúde: liberdade ou necessidade? Algumas considerações sobre os nexos constituintes das práticas de integralidade. In: PINHEIRO, R.; MATTOS, R.A. (Orgs.). Construção social da demanda: direito à saúde, trabalho em equipe, participação e espaços públicos. Rio de Janeiro: UERJ-IMS, ABRASCO, 2005, p. 11-29.

REVEL, J. Michel Foucault: conceitos essenciais. São Carlos: Claraluz, 2005.

ROLNIK, S. Cartografia sentimental: transformações contemporâneas do desejo. Porto Alegre: Sulina, Editora da UFRGS, 2006.

ROTELLI, F. A instituição inventada. In: NICÁCIO, F. (Org.). Desinstitucionalização. São Paulo: Hucitec, 1992, p. 13-32.

ROTELLI, F.; LEONARDIS, O.; MAURI, D. Desinstitucionalização, uma outra via: A reforma psiquiátrica italiana no contexto da Europa Ocidental e dos "países avançados". In: NICÁCIO, F. (Org.). Desinstitucionalização. São Paulo: Hucitec, 1992, p. 17-59.

SANTOS, M. O papel ativo da Geografia, um manifesto. In: Território, ano V, n. 9, jul.- dez., 2000.

SANTOS, M. A natureza do espaço. Técnica e tempo. Razão e emoção. São Paulo: Editora da Universidade de São Paulo, 2002.

Por uma outra globalização: do pensamento único à consciência universal. Rio de J aneiro: Recorde, 2003.

SILVA JÚNIOR, A.G. Modelos tecnoassistenciais em saúde: o debate no campo da saúde coletiva. São Paulo: Hucitec, 1997.

SILVA, R. V. B.; STELET, B. P.; PINHEIRO, F.; GUIZARDI, F. L. Do elo ao laço: o agente comunitário na construção da integralidade em saúde. In: PINHEIRO, R.; MATTOS, R. A. (Orgs.). Cuidado: as fronteiras da integralidade. Rio de Janeiro: CEPESC/UERJ, ABRASCO, 2005, p. 75-90.

SILVEIRA, M. L. Espaço geográfico: da perspectiva geométrica à perspectiva existencial. GEOUSP - Espaço e Tempo, São Paulo, n.19, p. 81-91, 2006.

TARDE, G. Monadologia e sociologia e outros ensaios. São Paulo: Cosac Naify, 2007.

TENÓRIO, F. A psicanálise e a clínica da reforma psiquiátrica. Rio de Janeiro: Rios Ambiciosos, 2001. 


\section{Endereço para correspondência}

Ruben Artur Lemke

Universidade para o Desenvolvimento do Estado e da Região do Pantanal, Av. Ceará, no 333, CEP 79003-010, Caixa Postal 2153, Campo Grande, Mato Grosso do Sul - MS, Brasil

Endereço eletrônico : rubenlemke@yahoo.com.br

Rosane Azevedo Neves da Silva

Rua Ramiro Barcelos, 2600, sala 13, CEP 90035-003, Porto Alegre-RS, Brasil

Endereço eletrônico : rosane.neves@ufrgs.br

Recebido em: 24/07/2009

Aceito para publicação em: 05/10/2009

Acompanhamento do processo editorial: Deise Mancebo, Marisa Lopes da Rocha e Roberta Romagnoli.

\section{Notas}

* Psicólogo, mestre em Psicologia Social e Institucional pela UFRGS

**Psicóloga, doutora em Educação pela UFRGS

${ }^{1} \mathrm{O}$ presente artigo é um capítulo modificado da dissertação "A I tinerância e suas I mplicações na Construção de um Ethos do Cuidado", defendida no Programa de Pós-graduação em Psicologia Social e Institucional da UFRGS em maio de 2009.

2 O Distrito Sanitário é a unidade mínima do sistema de saúde com base territorial/populacional. É composto por um conjunto de equipamentos que têm o objetivo de promover ações de prevenção e recuperação da saúde e garantir o acesso a níveis mais complexos de atenção pelo mecanismo de referência e contrarreferência. O Distrito Sanitário se situa nos marcos teóricos do modelo assistencial "Sistemas Locais de Saúde" (SILOS). Os SILOS foram propostos pela Organização Pan-Americana da Saúde como estratégia prioritária para garantir o ideal de "Saúde para todos no ano 2000". A implantação do modelo visa à reorientação dos sistemas nacionais de saúde. No Brasil, foi utilizado como estratégia para ampliar a cobertura assistencial e muitos dos seus princípios foram incorporados ao SUS (SILVA JUNIOR, 1996).

3 Essa noção de território usado aparece em um manifesto assinado por Milton Santos e seu grupo de trabalho em um encontro nacional de geógrafos em 2000, que tinha a intenção de romper com a idéia de que a geografia é uma disciplina que se ocupa estritamente de localizações ${ }^{1}$. Os autores propuseram que o objeto da geografia seja o "território usado" - entendido como resultado do processo histórico e base material e social das ações humanas - para obter uma concepção abrangente da totalidade das causas e dos efeitos dos processos socioterritoriais e assim construir teorias sociais, com propostas de intervenção que não sejam redutoras (SANTOS, 2000).

${ }^{4}$ Segundo Silveira (2006) na compreensão do espaço costuma existir o primado da extensão. Historicamente as ciências geográficas têm se ocupado predominantemente da extensão e sua operacionalização: demarcar as distâncias, as formas, os tamanhos e os limites. A estes estudos, que têm o extenso como o centro da reflexão metodológica a partir do qual se criam matematizações do espaço e uma concepção geométrica do mesmo, a autora denomina "epistemologia da extensão". Para contrapor este primado, a autora propõe uma "epistemologia da existência", porque o espaço geográfico é habitado, percorrido e humanizado e existir é estar no mundo em situação.

${ }^{5}$ É um termo retirado de François Perroux que se referia a um "espaço banal" em oposição ao espaço econômico (SANTOS, 2003). Em "A natureza do espaço" de 1996, o autor define espaço banal como "espaço de todas as pessoas, de todas as 
empresas e de todas as instituições, capaz de ser descrito como um sistema de objetos animado por um sistema de ações" (SANTOS, 2002, p. 283).

6 É claro que qualquer procedimento de busca ativa sempre tem um caráter eminentemente político. O que pretendemos evidenciar é o sentido político que a literatura, os textos das políticas e normativas técnicas passam a atribuir.

${ }^{7}$ Esse sentido pode ser encontrado na Política do Ministério da Saúde para Atenção Integral a Usuários de Álcool e Outras Drogas de 2004 com o termo procura ativa (BRASIL, 2004c) e na descrição que Nardi e Rigoni (2005) fazem das práticas dos redutores de danos.

8 A autora conta que vita activa na tradição ocidental é considerado hierarquicamente inferior à vita contemplativa, porque enquanto a primeira se ocupa das coisas mundanas, a segunda se ocupa da experiência do eterno.

9 A autora lembra das expressões latinas "inter homines esse" (estar entre homens), para designar viver, e "inter homines esse desinere" (deixar de estar entre homens), para designar morrer entre os romanos, um povo altamente político.

${ }^{10}$ Essas inquietações que os negócios do mundo nos produzem têm ressonância com o conceito de implicação de Lourau (1993). A implicação fala da relação que se estabelece entre o sujeito e as coisas do mundo, em que não existem mais dois pólos estáveis de sujeito e do objeto mundano, mas uma conexão que desestabiliza os pólos da relação num movimento de mútua transformação. Essa transformação que ocorre, seja por atração seja por propagação, dá-se quando nas práticas, os encontros fortuitos ou os pequenos acontecimentos, funcionam como partículas atratoras, produzindo perturbações ou desvios (KASTRUP, 2007a). Gabriel Tarde (2007) alegou que só podemos conhecer aquilo que nós temos em comum com o mundo.

${ }^{11}$ Biopoder, para Foucault, se refere ao modo como as estratégias de poder passam a se ocupar não apenas do governo dos indivíduos, através das técnicas disciplinares, mas pelas tecnologias e conjuntos que constituem populações. Este conjunto de biopoderes que se ocupam das populações, forma o que Foucault denomina Biopolítica, que é a economia política da vida, o modo como o poder investiu a vida, o corpo, o desejo e a sexualidade. Dentre estes biopoderes, se incluem as políticas de saúde (REVEL, 2005).

${ }^{12}$ Resistência entendida no sentido atribuído por Foucault no texto "Não ao sexo rei" como algo coextensivo ao poder, devendo, portanto, ser "tão inventiva, tão móvel, tão produtiva quanto ele" (FOUCAULT, 1999, p. 241).

${ }^{13}$ As práticas de liberdade, para Foucault (2006), consistem na ação de praticar a liberdade com ética, enquanto a ética é a forma refletida de liberdade. Nardi e Silva (2005) entendem a ética como o exercício de problematização dos modos de existência, problematização das formas como o sujeito se constitui na relação consigo e na relação com o mundo.

${ }^{14}$ No sentido de Foucault (2006), de criar uma estética de existência, conforme "A ética do cuidado de si como prática de liberdade".

${ }^{15}$ Kastrup (2007b) trabalha pormenorizadamente este tema, a ao falar da atenção do cartógrafo em campo. 